\title{
La fiscalidad y el mercado interno colonial en la historiografía americanista
}

\author{
María Ángeles Gálvez Ruiz
}

Universidad de Granada

Un repaso historiográfico de las diversas interpretaciones sobre la crisis del siglo XVII ha servido como punto de reflexión para analizar la economía mexicana durante los siglos XVII y XVIII, y para entender de una manera global la economía colonial, cuya transformación y reajuste fue indudable a partir del siglo XVII. Los mercados internos toman el relevo al comercio exterior como base de crecimiento general, lo cual nos ha permitido un nuevo punto de partida para presentar algunas de las líneas maestras en el campo de la investigación en torno al tema del mercado interno colonial y lo que han aportado los estudios de carácter fiscal sobre el análisis de los mercados regionales en la América colonial.

Atendiendo a los debates y discusiones en torno a la historiografía económica me remito en el presente análisis al tema de la fiscalidad y a la problemática del mercado interno colonial, ya que considero esta propuesta ilustrativa de una de las tendencias historiográficas más interesantes en la historia económica de la América española.

No se tratará aquí de dar una lista interminable de trabajos realizados en los últimos años en los temas propuestos, sino más bien de exponer algunas de las grandes líneas historiográficas y de investigación llevadas a cabo por historiadores. En sus trabajos se han planteado ciertas cuestiones históricas con aportaciones realmente importantes y, sobre todo, novedosas tanto por la metodología empleada como por sus análisis tan sugerentes.

Pero antes de entrar en dicho debate sería conveniente hacer mención de otra polémica suscitada varias décadas atrás para comprender de una manera global el tema. Me refiero a la existencia o no de una crisis general en el nuevo continente durante el siglo XVII. En este sentido, haremos un breve repaso a otros trabajos que se ocuparon del tema y presentaron una revisión historiográfica al respecto, haciendo especial hincapié en el caso mexicano.

\section{Estancamiento y crisis en la economía mexicana}

En 1990, Rosario Sevilla Soler presentaba un estado de la cuestión sobre la minería americana y la crisis del siglo XVII, ${ }^{1}$ cuyo análisis arran-

1 Sevilla Soler, Rosario: "La minería americana y la crisis del siglo XVII. Estado del problema”, Anuario de Estudios Americanos, sección de Historiografía y Bibliografía, T. XLVII, n. ${ }^{\circ} 2$, Sevilla, 1990, págs. 61-81. 
caba del estudio de los años 50 sobre la citada crisis en la historia europea. Desde que Eric Hobsbawn y Trevor-Roper plantearan en Past and Present una crisis de la Europa del seiscientos — crisis económica y crisis social respectivamente-, la polémica quedó abierta y suscitó la existencia de una crisis paralela americana, directamente relacionada con un descenso en el envío de remesas de metales preciosos al viejo continente. ${ }^{2}$ E. Hamilton ya había expuesto la cuestión en 1934 conectándola con la revolución de los precios en España; dos décadas después fue retomada por W. Borah y P. y H. Chaunu, cuyas conclusiones expresaban una decadencia de la economía americana, manifestada por un descenso en la producción de plata. ${ }^{3}$ Tesis que sería nuevamente discutida en los años 70 desde diversos puntos de vista por J. Lynch, P. Bakewell, D. Brading y H. Cross, A. Jara, M. Morineau y J. Israel. ${ }^{4}$

Sevilla Soler expone en su análisis una revisión historiográfica de las principales aportaciones sobre este tema, centradas básicamente en los años 70 hasta mediados de la década siguiente, y cuyos núcleos temáticos de interés giran en torno a la importancia de la minería en la economía colonial, la mano de obra, la financiación y producción de dicho sector. Este examen historiográfico ha permitido poner de manifiesto que la gran crisis económica del siglo XVII fue una crisis fundamentalmente española y europea, y no americana; que si hubo un descenso de las remesas de plata enviadas a España y una caída del comercio atlántico no fue originado por un declive de la producción de plata ya que durante toda la centuria se siguió produciendo este metal precioso en grandes cantidades, sino que fue consecuencia de un "reajuste de la economía colonial". Este análisis nos sirve como punto de partida para estudiar otros trabajos que han aportado nuevas reflexiones sobre el tema.

2 Past and Present, núms. 5 y 6, Oxford, 1954, y núm. 16, Oxford, 1959.

3 Hamilton, Earl J.: American treasure and the price revolution in Spain, 1501-1650. Cambridge, Massachussets, 1934; Borah, Woodrow: New Spain's Century of Depression, IberoAmericana, n. ${ }^{\circ} 35$, Berkeley, University of California Press, 1951; Chaunu, Pierre y Huguette: Séville et l'Atlantique (1504-1650), París, 1955.

4 Lynch, John: España bajo los Austrias. Barcelona, 1975; Bakewell, Peter: Minería y Sociedad en el México Colonial. Zacatecas, 1546-1700, México, 1976; Brading, David, y Harry Cross: "Colonial Silver Mining: México and Peru", The Hispanic American Historical Review, vol. LII, núm. 4, Durham, 1972, págs. 566-577; Jara, Alvaro: Tres Ensayos sobre Economía Minera HispanoAmericana, Santiago de Chile, 1966; Morineau, Michel: "Des Mètaux Prècieux Americains au XVII et au XVIII Siècles et leur Influence”. Bulletin de la Societe D'Histoire Moderne, núm. 1, París, 1977, págs. 17-27; Israel, Jonathan: "Mexico and the General Crisis of the Seventeenth Century", Past and Present, núms. 63, Oxford, 1974, págs. 33-57. Trad. en Ensayos sobre desarrollo económico de México y América Latina (1500-1975). Coord. E. Florescano. México, 1979. 
Morilla Critz analizó la situación de crisis y transformación de la economía del siglo XVII para el caso de la Nueva España. ${ }^{5}$ Considerando algo exagerada la afirmación de E. Florescano e I. Gil de que el período comprendido entre 1640 y 1740 se define como un siglo de depresión económica para México, ${ }^{6}$ el hilo conductor de su análisis respecto a la supuesta crisis ha sido un repaso por las distintas corrientes historiográficas, para llegar a una interpretación global de la economía de la colonia en el siglo XVII. Presenta diversos testimonios que sustentan la tesis de crisis económica, apoyándose en causas de diversa índole que llegan a determinar el tipo de crisis: crisis demográfica, de comercio exterior, de producción de plata, de los sectores agrícola e industrial o crisis política y social. ${ }^{7}$ Muchas de estas aportaciones han sido de gran relevancia y aunque la mayoría hoy ya están superadas o mayormente matizadas por investigaciones más recientes, algunas todavía cuentan con fieles seguidores. El estudio de François Chevalier, por poner un ejemplo, sobre la consolidación de la gran hacienda mexicana durante el siglo XVII, considerada como una estructura de producción bajo signo de regresión, ha sido aceptado tradicionalmente por estudiosos como Gibson, S. Zavala y hasta 1970 por E. Florescano, y pervive su influencia en autores como E. Semo, Barbosa-Ramírez o M. Carmagnani. ${ }^{8}$

En este repaso historiográfico se pueden observar distintas periodizaciones respecto a la crisis. Para Chaunu el período de crisis es entre 1630 y 1650, para Max Leod está situado entre 1635-1720; ${ }^{9}$ Berthe lo establece entre 1630-1680; ${ }^{10}$ incluso Bakewell señala, aunque en un tono menor y

5 Morilla Critz, José: "Crisis y Transformación de la Economía de Nueva España en el siglo XVII. Un ensayo crítico”, Anuario de Estudios Americanos, T. XLV, Sevilla, 1988, págs. 241-272.

6 Florescano, E., y Gil Sánchez, I.: "La época de las reformas borbónicas y el crecimiento económico, 1750-1808”, Historia General de México, vol. I, México, 1981 (3. a ed.), pág. 473.

7 Para la crisis demográfica hay que citar entre otros: Sherburne F. Cook, Woodrow Borah, José Miranda, Günter Vollmer y Claude Morin; para la crisis del comercio exterior: Pierre y Huguette Chaunu y Earl J. Hamilton; para la crisis en la producción de plata: M. Bargalló, R. West, Primo F. Velázquez, José F. de la Peña; para la crisis agrícola e industrial: W. Borah — para el sector de la seda en México-, F. B. Sandoval y J. P. Berthe — para las plantaciones de azúcar-, P. F. Velázquez, R. West y L. Cháves Orozco; para la crisis en el orden político y social: R. A. Humphreys y Ch. R. Boxer, W. Jiménez Moreno y J. Israel. Véase bibliografía en Morilla Critz, "Crisis y...”, págs. 243-249.

8 Chevalier, François: La formación de los latifundios en México. Tierra y sociedad en los siglos XVI y XVII, México, 1976. Morilla Critz, “Crisis y...”, pág. 247.

9 Mac Leod, J. M.: Spanish Central America: a socioeconomic history, 1520-1720, BerkeleyLos Ángeles, 1973.

10 Berthe, J. P.: "Xochimancas: les travaux et les jours dans une hacienda sucrière du Nouvelle-Espagne au XVII siècle”, Jahrbuch für Geschichte von Staat Wirtschaft und Gesellschaft Lateinamerikas, III, Koln, 1966, págs. 88-117. 
muy matizado - para Zacatecas, pero no general para Nueva España-, los años de 1640 a 1660; para Florescano y Gil el período clave es 1640-1740; y Chevalier sitúa la crisis en los primeros años de siglo, seguido de un prolongado estancamiento hasta prácticamente el reformismo borbónico.

En torno a las diferentes tesis de depresión y sus periodizaciones, Morilla Critz establece dos grupos respecto a dichas explicaciones de crisis, atendiendo básicamente a su conceptualización económica: a) crisis de demanda provocada por un descenso en la producción de plata b) crisis en la producción y circulación de mercancías, consecuencia de la política fiscal y de las prácticas mercantilistas impuestas por la metrópoli. La primera explicación viene dada por el convencimiento de que existe una correlación entre descenso de exportación y limitación de producción. La segunda explicación deriva de lo que se ha entendido como "los sacrificios exigidos a México para sostener el complejo imperial español". ${ }^{11}$ A raíz de estas explicaciones, Morilla Critz realiza una crítica a la visión de una depresión general, apoyándose en trabajos tales como el de Morineau, Linch, o TePaske y Klein, ${ }^{12}$ para llegar a la conclusión de que no hubo un descenso general de la producción de plata en Nueva España en el siglo XVII, incluso que no fue tan acusado el descenso de las exportaciones como se ha puesto de manifiesto repetidas veces. Es mas, se ha comprobado que tendencialmente los ingresos de la tesorería central de México aumentaron en esta centuria, pero que también una proporción cada vez mayor se gastaba en el propio virreinato. Así pues, se podría decir que el siglo XVII novohispano no se puede estudiar desde una perspectiva de depresión general sino, de una forma más acertada, bajo las importantes transformaciones que operaron al interior de la colonia, y donde los mercados internos van a sustituir al comercio exterior como base de crecimiento. Si Morilla Critz afirma de manera rotunda "que hay motivos suficientes para considerar que Nueva España asistió en el siglo XVII a una transformación, que comenzó a sacar a la colonia de la característica dependencia económica de la metrópoli", ${ }^{13}$

11 Morilla Critz, "Crisis y...”, pág. 254.

12 Morineau, Michel: "Le siècle XVII", Histoire économique et sociale du monde. Dirigida por P. Leon, tomo II. París, 1978, págs. 80-85; Lynch, John: España bajo...; TePaske, John J., y Herbert S. Klein: "The Seventeenth-century crisis in New Spain: myth or reality?, Past and Present, 90, Oxford, 1981, págs. 116-161.

13 En base a cuatro factores básicos se caracteriza dicha transformación: desarrollo e integración de los mercados locales y regionales, mayor proporción de recursos públicos generados en el interior, incremento de la eficacia productiva en las haciendas agroganaderas, posible aumento de la producción de plata y mayor retención de ésta en el virreinato. 
sin embargo, no rechaza totalmente la idea de crisis, aunque no se trata de una crisis económica general como había planteado la historiografía tradicional, sino que - como ha señalado - se trata de una crisis de la sociedad colonial con respecto a los valores del siglo anterior, y sobre todo de una crisis del poder virreinal.

María Elisa Martínez de Vega sigue muy de cerca el planteamiento de Morilla Critz al formular una serie de reflexiones en torno a la crisis del siglo XVII, donde determina el problema de ésta necesariamente en dos dimensiones diferentes: la europea y la americana. ${ }^{14}$ Siendo fundamental para la autora conocer el carácter y la evolución de las relaciones entre Europa y la América Española, estudia a John H. Elliott y a Tibor Wittman, que recoge las teorías de André Gunder Frank y E.R. Wolf sobre como dicha relación fue determinante "no sólo para dilucidar las leyes del mercado mundial naciente, sino para esclarecer también el modo de producir que se iba desarrollando en las Indias". ${ }^{15}$

En cuanto a la especificidad del ámbito novohispano, Martínez de Vega presenta un estado de la cuestión, siguiendo básicamente a John Lynch sobre el problema de la influencia y traslado de la crisis europea a América, y a Jonathan Israel, que define el siglo XVII mexicano como un siglo de conflictos sociales y de crisis del poder virreinal. ${ }^{16}$ Expone las tesis tradicionales que han sido objeto de revisión en las últimas décadas, repasando algunos trabajos sobre las cuestiones demográficas y sobre la supuesta grave crisis económica de México en esta centuria, destacando entre otras la visión dada por Chiaramonte, que diferencia la evolución de la población indígena en México y la de la población española, y la no correlación entre las tendencias demográficas de la población indígena con la evolución de determinados sectores productivos, entre ellos la producción minera. ${ }^{17}$ Por último, Martínez de Vega concluye con la misma propuesta que ya señaló Morilla Critz, de que el siglo XVII novohispano hay que estudiarlo bajo la óptica de una importante transformación en la que los

14 Martínez de Vega, M. ${ }^{a}$ Elisa: "Los mercaderes novohispanos: control virreinal y fraude fiscal en el primer tercio del siglo XVII". Revista Complutense de Historia de América, n. ${ }^{\circ}$ 87, 1994, págs. 87-128.

15 Elliott, John H.: "América y el problema de la decadencia española", y Wittman, Tibor: "La crisis europea del siglo XVII e Hispanoamérica", ambos en Anuario de Estudios Americanos, T. XXVIII, Sevilla, 1971, págs. 1-23 y págs. 25-44.

16 Israel, J.: Razas, clases sociales y vida política en el México colonial, 1610-1670. México, 1980, págs. 220-250.

17 Chiaramonte, J. C.: "En torno a la recuperación económica novohispana durante el siglo XVII", Historia Mexicana, XXX, n. ${ }^{\circ}$ 4, México, 1981, págs. 561-604. 
mercados internos jugaron un papel fundamental en lugar del comercio exterior como base de desarrollo para el México colonial.

Una de las críticas más sólidas sobre las interpretaciones a la crisis la ofrece John H. Coastworth, ${ }^{18}$ que revive en su artículo la disputa sobre la supuesta depresión del siglo XVII expuesta en los años 50 por Woodrow Borah para el virreinato de Nueva España, rebatida treinta años más tarde por Herbert Klein y John TePaske al querer demostrar, con sus estudios basados en los ingresos fiscales, que más que depresión lo que hubo fue un estancamiento de la economía. ${ }^{19} \mathrm{Si}$ las rentas fiscales eran constantes, es decir si éstas no habían decaído, tampoco por consiguiente había tal crisis económica. Pero el trabajo de Klein y TePaske apoyado en los ingresos fiscales presentaba varias dificultades, en opinión de Coatsworth. En primer lugar, el hecho de que hasta ahora no se tenga un índice de precios adecuado para la economía mexicana del siglo XVII que permita reflejar los efectos de la inflación. El segundo problema deriva de la relación entre dicho estancamiento de las rentas fiscales y el aumento al doble en población, como parece que ocurrió, basándose en los trabajos sobre la población de la Nueva España en el siglo XVII de Woodrow Borah y Sherburne F. Cook. ${ }^{20}$ Por fuerza, el producto per cápita se debió reducir a la mitad, y por tanto "la productividad de la economía en 1699, entonces, sería la mitad de la de $1600 " .{ }^{21}$

Con este planteamiento Coatsworth quiso llegar a conclusiones similares a las de Klein y TePaske respecto a la tesis de un estancamiento en la economía del siglo XVII en Nueva España, pero a través de un análisis diferente al que había impulsado los trabajos de ambos autores, cuestionando pues, igualmente, la depresión de la economía mexicana en el siglo XVII.

El desencuentro de las formulaciones de Coatsworth con las de Klein y TePaske arranca del mismo análisis sobre las condiciones de la economía en el siglo XVI. Para estos últimos, los datos basados en las rentas muestran prosperidad y crecimiento económico, para Coatsworth, y esta puede

18 Véase un estado de la cuestión en John H. Coatsworth: "La historiografía económica de México", Los orígenes del atraso. Nueve ensayos de historia económica de México en los siglos XVIII y XIX. México, 1990, págs. 21-36 (Versión original en la Revista de Historia Económica 4:2, Madrid, 1988, págs. 277-291).

19 TePaske y Klein: "The Seventeenth-Century...

20 Borah, Woodrow, y Sherburne F. Cook: The Indian Population of Central Mexico, 15311605, Ibero-Americana, n. ${ }^{\circ}$ 44, Berkeley, 1960; y Essays in Population History: Mexico and California, 3 vols. Berkeley, 1970.

21 Coatsworth, "La historiografía económica...”, pág. 24. 
ser su critica más severa a Klein y TePaske, no hubo depresión en el siglo XVII en México, por una sencilla razón "porque no hubo prosperidad en el siglo XVI". Es decir, una población en clara disminución fue mayormente concentrada de forma coactiva para trabajar en las empresas agrícolas, mineras y obrajeras de españoles, de tal forma que el aumento de las rentas fiscales para éstos iba a ser más que evidente, pero a costa de transferir mano de obra de un sector productivo a otro que lo era menos, con los consiguientes perjuicios que se podían derivar para la productividad económica en general. ${ }^{22}$

En relación con lo arriba expuesto ha llegado a ocupar un lugar destacado en la historiografía económica americanista la polémica y eterna cuestión de los costos del colonialismo español. Sobre las razones que determinaron la enorme distancia que separa hoy día la economía mexicana de aquéllas otras de naciones más desarrolladas, como la estadounidense, Coastworth delimita el período en el que se llegó a dicho atraso, entre los años 1780 y 1870, es decir, "en los albores de la edad contemporánea, y que de ninguna manera se debe a los efectos supuestamente perniciosos del imperialismo y de la dependencia de la actualidad" ${ }^{23}$ De dicha afirmación se desprenden varias cuestiones importantes. En primer lugar, hay que buscar las causas iniciales, según el autor, en unos transportes inadecuados y en la ineficiente organización económica. ${ }^{24}$ Las dificultades de comunicación afectaron de forma muy negativa a los costes del transporte, al desarrollo de los mercados y al aumento de la productividad. ${ }^{25}$ Asimismo durante el período colonial la rigidez y límites legales impidieron el desarrollo de una verdadera economía mercantil, limitaciones que continuaron en la centuria siguiente. Segundo, con la Independencia no se logró un verdadero cambio en la organización interna de la economía, dada la resistencia de la élite criolla y de la Iglesia a las transformaciones institucionales necesarias. En tercer lugar, y consecuencia de lo anteriormente expuesto, no se debe acudir a los clásicos cortes cronológicos, como hasta ahora se ha veni-

22 Ibídem, pág. 27.

23 Ibídem, pág. 22.

24 Coastworth, John H.: "Los obstáculos al desarrollo económico en el siglo XIX", en Los orígenes del atraso..., pág. 94. (Versión original en American Historical Review, 83: 1, 1978, págs. 80-100).

25 Sergio de la Peña también ha hecho hincapié en los elevados costes del transporte, caracterizado por una extrema lentitud y el uso preferente de recuas en vez de carretas. A ello añade la gran cantidad de impuestos al comercio, al transporte y a la producción de bienes, cuyas consecuencias eran "la indiferencia por la inversión productiva en las colonias y la estricta distribución de factores que impedían su movilidad, lo que a su vez incidía sobre el comercio". Peña, Sergio de la: La formación del capitalismo en México, México, 1987 (14. ${ }^{a}$ ed.), pág. 63. 
do realizando, estudiando por un lado el período colonial, y por otro, el período independiente, ambos de forma aislada, entre otras razones porque se necesitan establecer tendencias de larga duración para una mejor comprensión de la continuidad, como es el caso que nos ocupa, de las estructuras socio-económicas.

Varios estudios de tipo regional y por sectores económicos apuntan igualmente ciertos descensos o estancamiento en los niveles de productividad a partir de la década de 1770 en México. Es decir, la expansión económica del siglo XVIII mexicano se ve interrumpida, o al menos reduce su ritmo de crecimiento, a partir del último tercio. Se advierten tales indicios en los datos que ofrecen trabajos como el de Brading, que se centró en el caso de Guanajuato y la minería, ${ }^{26}$ el de Van Young para la región de Guadalajara tanto en la ciudad como en el campo y la hacienda, ${ }^{27}$ el de Claude Morin sobre la región de Michoacán, que realizó una investigación serial para estudiar el movimiento de la población, de la producción y de los intercambios, ${ }^{28} \mathrm{O}$ el de Richard Salvucci, quien se centró en el sector de la industria textil en el México colonial..$^{29} \mathrm{~A}$ tales estudios habría que añadir los de Klein y TePaske, quienes fechan los años de inicio de la decadencia entre 1770 y $1790 .{ }^{30} \mathrm{Si}$ hubo crecimiento e incluso aumento de la productividad en el México del siglo XVIII, estos fueron finalmente contrarrestados o anulados por los efectos que se derivaron del sistema político de dominio español. Coatsworth añade que las instituciones y leyes eran los límites principales del absolutismo colonial a la economía mexicana del siglo XVIII. ${ }^{31}$ Pero, además, la fuerte intervención del Estado y las medi-

26 Brading, David A.: Mineros y comerciantes en el México borbónico (1763-1810), México, 1975.

27 Van Young, Eric: La ciudad y el campo en el México del siglo XVIII. La economía rural de la región de Guadalajara, 1675-1820, México, 1989.

28 Morin, Claude: Michoacan en el Nueva España del siglo XVIII. Crecimiento y desigualdad de una economía colonial, México, 1979.

29 Salvucci, Richard: Textiles and Capitalism in México. An Economic History of the Obrajes, Princenton, 1987.

30 TePaske y Klein: "The Seventeenth Century...; TePaske, "General Tendencies and Secular Trends in the Economies of Mexico and Peru, 1750-1810: The View from de Cajas of Mexico and Lima", en Nils Jacobsen y Hans Jürgen Puhle (comp.): The Economies of Mexico and Peru During the Late Colonial Period, 1760-1810, Berlin, 1986; y Klein, "La economía de la Nueva España, 16801809: un análisis a partir de las Cajas Reales”, Historia Mexicana, XXXIV, núm. 4, México, 1985, págs. 561-609.

31 Coatsworth, John H.: "Los límites del absolutismo colonial: Estado y economía en el siglo XVIII", en Los orígenes del atraso..., págs. 37-56. (Versión original en Karen Spalding (comp.), Essays in the Political, Economic and Social History of Colonial Latin America, Newark, Delaware, 1982, págs. 25-51). 
das de exacción al excedente económico supusieron igualmente una seria traba al desarrollo económico de México. ${ }^{32}$ Aquí quedan referidas de nuevo las cargas fiscales impuestas por el estado absolutista con objeto de impedir cualquier tipo de acción ilegal que burlara el pago de los impuestos, y que significaron un grave obstáculo para el desarrollo de los principales centros de producción, del comercio y de los mercados, consecuencia directa de la política fiscal americana dictada por el gobierno de la metrópoli.

De todas formas, tras la ruptura del orden colonial no asistimos a una mejora económica en México, antes bien, sostiene Coatsworth, con el nuevo período independiente la economía que había sufrido la gran caída entre 1780 y 1810 , conoce aún un prolongado estancamiento hasta prácticamente la restauración de la República en 1867.

Ruggiero Romano coincide con Coastworth en señalar una absurda legislación impuesta desde la metrópoli, que "sofocaba" las economías americanas. El autor presenta una interesante reflexión sobre los problemas del comercio, en el contexto internacional entre España e Hispanoamérica, ${ }^{33}$ afirmando que "la caída del comercio en el siglo XVII es un hecho que se refiere a la crisis de España, pero no así a América, que tiene todavía la fuerza de absorber productos europeos". Como vemos, R. Romano también señaló el problema en torno a la supuesta depresión del siglo XVII en el continente americano, y la pérdida de importancia del monopolio español, sobre todo a partir de la segunda mitad del siglo XVII, frente a la organización de un comercio de contrabando "semilegal". ${ }^{44}$ Centrándose en el tema del comercio colonial exterior, la raíz del problema se encuentra, según el autor, en esa incapacidad de España para responder a las exigencias del comercio exterior, por las deficiencias que presenta tanto para importar como para exportar. Añade Romano que las razones de esta incapacidad hay que buscarlas en la consideración de que Hispanoamérica fue vista por los españoles como una fuente "parasitaria"

32 Coatsworth, "Los obstáculos al desarrollo económico...”, págs. 80-109.

33 Romano, Ruggiero: "Algunas consideraciones sobre los problemas del comercio en Hispanoamérica durante la época colonial”, Consideraciones. Siete estudios de historia, Lima, 1992, págs. 161-209.

34 Se realizaba a través de escalas imprevistas de barcos en puertos por causa del mal tiempo o averías, solicitando una licencia a las autoridades del puerto para atracar. De esta manera se establecía este comercio que Romano llama "semilegal", aunque en realidad se trataba de un comercio de contrabando que contaba con el consentimiento de las autoridades locales. Romano, Ruggiero: Coyunturas opuestas: la crisis del siglo XVII en Europa e Hispanoamérica, México, 1993, pág. 135. 
de renta, a diferencia de los extranjeros que empezaron a ver en tierras americanas un mercado y una fuente de beneficios sustanciosa. A esa incapacidad española se debe añadir por contrapartida la extraordinaria capacidad de absorción del mundo hispanoamericano. Es aquí donde, a juicio del autor, radica el principal problema, que nos lo resume así: "El 'Imperio' de América muestra un apetito extraordinario durante el siglo XVII. Si España no es capaz de satisfacerlo, es reflejo de la crisis española del siglo XVII y no de la crisis americana. Insisto: en lo que se refiere al comercio internacional, la América española no presenta ninguna señal de crisis en el siglo XVII". ${ }^{35}$ Así pues R. Romano, niega igualmente dicha crisis para las colonias de ultramar del siglo XVII, al menos en lo que concierne al comercio colonial exterior.

\section{Los estudios fiscales sobre la América española}

Presentadas algunas de las discusiones que atienden a los problemas de la supuesta depresión del siglo XVII en América, y más concretamente al caso novohispano, pasamos a ver el avance que en las dos últimas décadas ha experimentado la historiografía respecto al tema de la fiscalidad en la América colonial.

La consulta de las cuentas de la Real Hacienda como fuente histórica tomó un fuerte impulso a partir de los trabajos de John J. TePaske y Herbert S. Klein. Ambos autores trabajaron los datos obtenidos a partir de las Cajas Reales con la intención de estudiar el movimiento de los ciclos de la economía del imperio español en América ${ }^{36}$ Nos presentan un sumario de ingresos y egresos de cada caja real o distrito fiscal de la Nueva España, ofreciendo, por tanto, un panorama de las cuentas de la Real Hacienda para el conjunto del virreinato en la época colonial. De especial interés son las aclaraciones sobre las cartas-cuenta de las cajas y su manejo como fuente histórica. Una fuente sin duda muy rica para un mejor conocimiento de la historia socioeconómica de la Nueva España. Para el caso mexicano se conserva gran parte de esta documentación en el Archivo General de Indias — sección de Contaduría-, gracias al envío de los libros contables a la Contaduría Mayor en España.

35 Ibídem, pág. 138.

36 Ingresos y egresos de la Real hacienda en Nueva España, México, 1986, 2 vols. 
Entre los numerosos estudios de ambos autores, ${ }^{37}$ cabe reseñar de Klein, "La economía de la Nueva España, 1680-1809: un análisis a partir de las cajas reales", donde se realizó una reconstrucción de las cuentas anuales de la Real Hacienda novohispana, poniendo en evidencia las relaciones entre las regiones, la economía desarrollada en cada una de ellas y lo ingresado en concepto de impuestos por cada ramo. Además de permitirnos apreciar la evolución que sufren dichas tesorerías a lo largo del período, esas cuentas reflejan variaciones regionales importantes. Partiendo de la idea, muy discutida hasta hoy, de que "el movimiento fiscal refleja los cambios fundamentales de la economía, se trata de averiguar qué nos dice ese movimiento acerca de la historia de la economía virreinal durante el período 1680-1809", ${ }^{38}$ los objetivos han sido crear un modelo sobre los ciclos y las tendencias de la economía de la Nueva España, a través de la información que se desprende de las cajas reales. ${ }^{39}$

A raíz de los trabajos de Klein y TePaske para el estudio de las Cajas Reales americanas, se han venido sucediendo diversas publicaciones en los últimos veinte años, cuyas aportaciones han enriquecido el panorama historiográfico para los estudios de fiscalidad en el campo americano.

En el caso español es obligado reseñar los trabajos de los años 70 de Ramón M. ${ }^{a}$ Serrera para el estudio de la ganadería en la región de Nueva Galicia ${ }^{40}$ que mostraron la realidad ganadera de esta región occidental de México a fines de la colonia, a través del análisis de diversos ramos impositivos - extracción de ganado, media annata, licencias de hierro-. ${ }^{41}$ Varios trabajos en este sentido, centrados en el estudio de los distintos ramos de las cuentas de Real Hacienda, se han venido realizando en las

37 Klein, Herbert S.: "Últimas tendencias en el estudio de la Hacienda colonial hispanoamericana", Papeles de Economía Española, n. ${ }^{\circ}$ 20, Madrid, 1984, págs. 39-48; TePaske, John J.: "La cuantificación en la historia colonial latinoamericana", Las dimensiones del pasado. Estudios de historia cuantitativa, Madrid, 1974, págs. 274-324; TePaske, "Recent trends in quantitative history: Colonial Latin American, Latin American Research Review, tomo X, n. ${ }^{\circ}$ 1, Austin, Texas, Spring, 1975, págs. 51-62; TePaske, La Real Hacienda de Nueva España: La Real Caja de México (1576-1816), México, 1976; TePaske y Klein, The Royal Treasuries of the Spanish Empire in America, 3 tomos, Durham, North Carolina, 1982.

38 Klein, “La economía de la Nueva España...”, pág. 592.

39 Tal vez la cuestión de la teorías apoyadas exclusivamente en las fuentes de carácter fiscal sea lo que más discuta Coatsworth, porque estas rentas no reflejan de forma adecuada "la tendencia de la economía en su totalidad" (Coatsworth, "La historiografía económica...", pág. 25).

40 Serrera, Ramón M.': Guadalajara Ganadera. Estudio Regional Novohispano, 1760-1805, Sevilla, 1977.

41 Serrera, Ramón M. a: "La contabilidad fiscal como fuente para la historia de la ganadería: el caso de Nueva Galicia”, Historia Mexicana, vol. XXIV, n. ${ }^{\circ}$ 2, México, 1974, págs. 177-205. 
últimas dos décadas en el panorama español, como por ejemplo las investigaciones llevadas a cabo por el grupo de historiadores de la Universidad de Alcalá de Henares, ${ }^{42}$ centradas en las fuentes de las cajas auríferas neogranadinas ${ }^{43}$ cuyas cifras nos muestran la producción legal de oro en la segunda mitad del siglo XVII. El trabajo de prospección ha sido llevado básicamente en la sección de Contaduría del Archivo General de Indias, pero igualmente se reconoce el vacío que puede haber entre la documentación conservada en Sevilla, y por tanto su necesidad de acudir entonces a los archivos americanos nacionales y provinciales. El trabajo ofrece ciertas orientaciones para el manejo de las cartas-cuenta de las reales cajas neogranadinas, con idea de conocer las principales fuentes de ingresos y gastos en cada territorio y su evolución durante el período colonial. ${ }^{44}$ La producción legal de oro fue calculada a través del ramo impositivo del quinto real, quedando anotado en las cartas-cuenta.

Aunque existen estudios como el de Sánchez Bella, ${ }^{45}$ que nos ofrece más que nada una historia institucional sobre la Real Hacienda, o la extensa obra de Fabián de Fonseca y Carlos de Urrutia, ${ }^{46}$ que presenta un estudio muy útil sobre los diversos ramos de hacienda, podemos decir que faltaban trabajos que nos explicaran mejor el funcionamiento del sistema fiscal colonial. Una aportación realmente novedosa ha sido la de H. S. Klein con su obra Las finanzas americanas del Imperio español 1680-1809, señalando las posibilidades que en materia de investigación ofrece la reconstrucción de las fuentes fiscales y el estudio de la estructura fiscal colonial. ${ }^{47}$ Se centra básicamente en un análisis detallado de los ingresos y egresos de tipo fiscal en los virreinatos de Nueva España y Perú y en la Audiencia de Charcas. Para el caso que nos interesa, es decir, los impuestos de tipo mercantil, estos

42 Lucena Salmoral (ed.), Manuel: "Fuentes para el estudio de la fiscalidad colonial: Las cajas auríferas neogranadinas en el siglo XVII. La producción de oro en el Nuevo Reino de Granada a través de las Cajas Reales (1651-1701)”, Estudios de Historia Social y Económica de América, n. ${ }^{\circ}$ 8, Alcalá de Henares, 1992 (núm. monográfico).

43 Trabajadas las cajas de Anserma, Antioquía, Cáceres, Guamocó, Mompox, Popayán, Remedios y Zaragoza.

44 Añaden "Pero también para conocer la realidad de las prioridades de la política económica de la corona en cada región y su alcance. Se puede llegar así al establecimiento de ciclos, para luego compararlos entre sí tratando de ver relaciones de dependencia, patrones de explotación semejantes o las diferencias entre las economías de los distintos distritos y el entendimiento con sus capitalidades o ciudades principales", en Lucena, "Fuentes para el estudio de la fiscalidad colonial...", pág. 25.

45 Sánchez Bella, Ismael: La organización financiera de las Indias. Siglo XVI, Sevilla, 1968.

46 Fonseca, Fabián de, y Carlos de Urrutia: Historia general de la real hacienda, México, Vicente G. Torres, 1845-1853 (6 tomos).

47 Klein, Herbert S.: Las finanzas americanas del imperio español, 1680-1809, México, 1994. 
"pueden brindar un importante conjunto de datos para estudiar la naturaleza del comercio y los mercados locales en América". ${ }^{48}$

Hoy está a debate lo que realmente aportan los estudios dedicados a la historia fiscal colonial, pues frente a los que apoyan sus investigaciones en los datos basados en los ingresos fiscales para determinar tendencias generales en la economía gravada, otros ponen en duda, o al menos en discusión, tal fin. Para empezar, los trabajos de Klein han determinado que el alza o la caída de los ingresos fiscales estaban muy relacionados con los índices de productividad de las regiones. Sin embargo, ya hemos visto lo que piensa Coatsworth respecto a la supuesta prosperidad del siglo XVI basada fundamentalmente en las cifras que arrojan los ingresos fiscales para dicho período. De todas formas, Klein igualmente advierte de los problemas y señala todo tipo de precauciones para la utilización correcta de las cifras que se desprenden de los registros fiscales. Consciente de ello, apunta los errores que llevaron a determinar la supuesta crisis en el siglo XVII novohispano, basados principalmente en las cifras de Hamilton, donde una decadencia del comercio transatlántico se corresponde con un descenso en la producción de las colonias. Además, en las cifras de tipo fiscal que arrojaban las cuentas mineras en la ciudad de México se registró un descenso de ingresos en la tesorería central de México, pero que no se corresponde en absoluto con una caída de producción minera, sino con la apertura de nuevos distritos fiscales en reales mineros recién descubiertos en el norte, que absorbieron caudales que antes se dirigían directamente a la caja matriz. ${ }^{49}$ Por tanto, debemos insistir en las limitaciones que nos imponen los estudios de carácter fiscal, y sobre las precauciones que se deben tomar para hacer una lectura y análisis correctos de las fuentes.

\section{Reflexiones acerca del Mercado Interno Colonial}

Con estas breves pinceladas sobre las ventajas y los inconvenientes que hallamos en los estudios que acuden a las fuentes fiscales y atienden al tema de las finanzas americanas, nos acercamos a un tema que guarda una estrecha relación con los estudios de fiscalidad; nos estamos refiriendo al del mercado interno colonial. Muchos estudios confirman hoy la existencia de mercados regionales semiautónomos, siendo de una gran uti-

48 Ibídem, pág. 164.

49 Ibídem, pág. 169. 
lidad los datos que arrojan las fuentes fiscales sobre estos mercados, es decir, lo que nos ofrece la renta de alcabalas para un mejor conocimiento de tales mercados.

No vamos a detenernos en lo que refleja el estudio de la renta de alcabalas - tanto sus alcances como sus límites-, pues existe una abundante literatura al respecto. Sólo diremos que la alcabala era desde el punto de vista hacendístico una renta real, y desde la óptica tributaria un impuesto que gravaba las transacciones mercantiles. En el caso de Nueva España desde finales del siglo XVII tiene el carácter de un impuesto a la circulación, ya que el pago debía efectuarse en el momento de introducirse los efectos en el suelo alcabalatorio, es decir, cuando el efecto objeto de transacción mercantil entraba por primera vez a un mercado regional, o bien pasaba de un alcabalatorio a otro..$^{50}$

Garavaglia y Grosso, en su estudio sobre las alcabalas novohispanas, nos descubren un complejo sistema en torno al cobro de dicha renta, la localización de este impuesto en las fuentes documentales, su utilización como sistema de reconstrucción para la circulación de mercancías, etc. ${ }^{51} \mathrm{La}$ utilidad de este trabajo consiste en su carácter clarificador, al mismo tiempo que presenta un análisis crítico sobre la fuente documental. Pero, sobre todo, nos indica muy bien lo que expresan las series de alcabalas, que como señalan: "las series de alcabalas y la fuente que aquí presentamos expresan algo más que el consumo y, precisamente, ese algo más se resume en lo que hemos denominado grado de actividad económica de una región". ${ }^{52}$

Los trabajos de Assadourian nos revelaron pronto la importancia de la fuente de alcabalas para el estudio del mercado interno y señalaron la necesidad de examinar el comercio local, frente al énfasis que había puesto la historiografía tradicional en los temas sobre el comercio de tipo internacional a través de los registros de almojarifazgo. ${ }^{53}$ La fuente alcabalatoria

50 Los principales problemas derivan de quedar exentos del pago ciertos géneros e introductores (población indígena, Iglesia, conventos y eclesiásticos en general), así como todo aquello comerciado por vías ilegales, como el contrabando, por lo que los registros de alcabalas sólo aprehenden una parte del conjunto del movimiento mercantil. Por otro lado, la variedad en la aplicación de la normativa y los particularismos regionales dificultan aún más su estudio.

51 Garavaglia, Juan Carlos, y Juan Carlos Grosso: Las alcabalas novohispanas (1776-1821), México, 1987.

52 Ibídem, pág. 59.

53 Estudios dedicados a este comercio, en concreto al comercio transatlántico, han sido entre otros los siguientes: Chaunu: Seville et l'Atlantique...; García Fuentes, Lutgardo: El comercio español con América (1650-1700), Sevilla, 1978; García-Baquero González, Antonio: Cádiz y el Atlántico (17171778), Sevilla, 1976, 2 vols.; Martínez Shaw, Carlos: Cataluña en la carrera de Indias, 1680-1756, Barcelona, 1981; y Ortiz de la Tabla, Javier: Comercio exterior de Veracruz, 1778-1821, Sevilla, 1978. 
fue utilizada por Assadourian para sus estudios en la región de Córdoba del virreinato del Río de la Plata. ${ }^{54}$ Las consultas de los libros de guías y libros alcabalatorios le permitieron reconstruir las exportaciones hechas a través de la aduana de Córdoba. Pero igualmente se puede realizar una reconstrucción cuantitativa de las importaciones puesto que todas las mercancías pagaban derechos de entrada a un mercado regional.

Assadourian propone la reconstrucción cuantitativa de las producciones y de los flujos mercantiles interregionales - tanto de entrada como de salida a un mercado- . Para este autor el estudio de los mercados regionales es fundamental para conocer la organización de un espacio económico determinado, no sólo por la reconstrucción de la circulación de mercancías y flujos mercantiles interregionales que operaban al interior de un territorio, sino también porque el estudio de estos mercados internos coloniales permite "reordenar la discusión sobre los modos de producción en América Latina". ${ }^{55}$

Las teorías desarrolladas sobre la formación del mercado interno colonial han sido expuestas en diversos estudios como el que hace referencia al espacio colonial peruano. ${ }^{56} \mathrm{El}$ conocimiento de la producción y circulación de mercancías nos lleva a definir un espacio económico determinado, a determinar la especialización regional del trabajo, que establece a su vez un sistema de intercambios entre distintas regiones del mismo espacio, cuya intensidad puede ser superior al intercambio con cualquier otra región externa, y finalmente nos permite ver la integración de dicho espacio económico. Ruggiero Romano también vio como a partir del siglo XVII las relaciones interamericanas se hicieron más complejas y como en ellas se pudo dar un sistema de circulación de mercancías entre diferentes regiones de cierta importancia; sin embargo, para Romano esto no quiere decir que nos hallemos ante la formación de un mercado interno, sino más bien ante la suma de varios mercados regionales ${ }^{57}$ Esta negación a la formación de un mercado interno ha sido también puesta de manifiesto por otros autores como Marcelo Carmagnani, para quien más que la formación de un mercado colonial único, lo que se da es un "proceso de agregación de diversos mercados regionales". ${ }^{58}$

54 Assadourian, Carlos Sempat: "El sector exportador de una economía regional del interior argentino. Córdoba, 1800-1860 (Esquema cuantitativo y formas de producción)", en El sistema de la economía colonial. El mercado interior, regiones y espacio económico, México, 1983, págs. 307-367.

55 Ibídem, págs. 11, 16.

56 Assadourian, "Integración y desintegración regional en el espacio colonial. Un enfoque histórico", en El sistema de la economía colonial..., págs. 127-154.

57 Romano, Coyunturas opuestas..., págs. 140-143.

58 Carmagnani, Marcelo: Les mécanimes de la vie économique dans une société coloniale: Le Chili (1680-1839), París, 1973, pág. 265. 
Assadourian llegó a definir el grado de autosuficiencia económica que había alcanzado el espacio peruano a fines del siglo XVI con dos polos de crecimiento que actuaron como motores de arrastre para el crecimiento regional polarizado, Potosí con la producción de plata y Lima con una función comercial monopólica. Pero dicha forma de integración se mostrará bastante vulnerable a ciertos cambios, hasta tal punto que se puede llegar a la quiebra y a la desintegración de dicho espacio, por la crisis en la producción de la plata de Potosí, y la crisis de Lima por la pérdida del control monopólico sobre las importaciones y la exportaciones del virreinato.

Klein advirtió el reflejo del brusco descenso en la producción de la plata potosina del siglo XVII, al igual que ocurrió en el Alto Perú, en los ingresos fiscales de sus respectivas tesorerías. E igualmente señaló como "las economías satélite" — al norte del Río de la Plata y valles agrícolas altoperuanos - se resintieron acusando fuertes bajas en sus niveles recaudatorios en las tesorerías locales, muy relacionado todo ello con una pérdida importante del mercado de Potosí. Klein dice al respecto: "Estos hallazgos apoyan las teorías de la integración regional propuesta por Carlos Sempat Assadourian, quien sostiene que en la América colonial española existían mercados regionales semiautónomos". ${ }^{59}$

Igualmente las teorías de Assadourian sobre el ciclo de circulación de capital minero, situaron la producción minera como la determinante en el desarrollo del proceso mercantil, tanto para el virreinato de la Nueva España como del Perú. ${ }^{60}$ Propone para un análisis correcto de la producción minera, la combinación de una orientación de dicha producción hacia el exterior y de sus efectos al interior del espacio colonial, poniendo en relación el sector minero con el resto de los sectores productivos, y cómo el proceso de circulación en la minería tiene como resultado final la formación de un sistema económico mercantil. ${ }^{61}$

59 Klein, Las finanzas americanas..., pág. 169.

60 En su definición del ciclo de circulación de capital minero dice: "el proceso de producción en la minería se manifiesta como un movimiento cíclico continuo que convierte una gran parte del producto final obtenido (plata, dinero) en capital variable, capital circulante y capital fijo. Esta serie de operaciones compone, en su conjunto, el ciclo de circulación de capital minero", Assadourian, "La organización económica espacial del sistema colonial", en El sistema de la economía colonial..., pág. 264.

61 Para el caso de la Feria de San Juan de los Lagos hemos podido comprobar la relación existente entre los asientos mineros del norte de México y los flujos mercantiles que operaban de forma periódica en torno a la feria. Gálvez, M. a Ángeles, y Antonio Ibarra: "Comercio local y circulación regional de importaciones. La Feria de San Juan de los Lagos en la Nueva España”, Historia Méxicana, vol. XLVI, núm. 3, México, 1997. 
La tesis sostenida por Assadourian sobre la formación del mercado interno colonial ha alentado diversas investigaciones que unen la historia económica de tipo serial con las teorías marxistas que caracterizan su obra. ${ }^{62}$ Sus hipótesis acerca del mercado colonial han inspirado la obra de Juan Carlos Garavaglia para la región de Paraguay, Mercado interno y economía colonial ${ }^{63}$ y la de Zacarías Moutoukias para el puerto de Buenos Aires. ${ }^{64} \mathrm{La}$ tesis de Malamud igualmente está influenciada por la obra de Assadourian, cuando trata el tema del comercio transatlántico y su articulación con el mercado interno. ${ }^{65}$

La investigación llevada a cabo por J. C. Grosso y J. C. Garavaglia para el comercio interno de Nueva España aparece en una línea muy cercana a los trabajos de Assadourian. Sus estudios para la región "histórica" de Puebla-Tlaxcala ${ }^{66}$ además de acudir a la fuente decimal —el diezmopara conocer la producción agrícola de la región, han servido para determinar su nivel de actividad económica en los últimos decenios del siglo XVIII acudiendo a la fuente de alcabalas y presentándonos los montos globales de las transacciones mercantiles regidas por dicho impuesto.

Asimismo Garavaglia y Grosso analizaron el mercado local de Tepeaca, mostrando la enorme complejidad económica y social de este mundo rural. ${ }^{67}$ Basándose en las alcabalas de Tepeaca, definieron el tipo de mercancías, tanto de productos de la tierra como de importación, así como el tipo de comerciante, proponiendo a su vez algunos criterios para su clasificación social entre mercaderes españoles, indios y mestizos y su posición o grado de participación en el mercado. De esta forma llegaron a definir el perfil del consumo, que frente a lo que tradicionalmente se ha venido considerando como un predominio casi absoluto del maíz, en Tepeaca las proteínas animales ocuparon un lugar destacado. Aún más relevante es el papel que jugarán en dicho mercado, junto a los hacendados y mercaderes impor-

62 Tandeter, Enrique: "El período colonial en la historiografía argentina reciente", Historia Mexicana, vol XLII, n. 3, México, 1993, págs. 789-819.

63 Garavaglia, Juan Carlos: Mercado interno y economía colonial, México, 1983.

64 Moutoukias, Zacarías: Contrabando y control colonial en el siglo XVII, Buenos Aires, 1988.

65 Malamud Rikles, Carlos Daniel: Cádiz y Saint Malô en el comercio colonial peruano (1698-1725), Cádiz, 1986.

66 "La región de Puebla/Tlaxcala en la Nueva España del siglo XVIII", Historia Mexicana, vol XXXV, núm 4, México, 1986, págs. 549-600.

67 Garavaglia, Juan Carlos, y Juan Carlos Grosso: "Comerciantes, hacendados y campesinos. Un mercado local en el valle poblano (Tepeaca, 1792)"; Grosso, Juan Carlos, y Jorge Silva Riquer: Mercados e Historia, México, 1994 (Publicado originalmente en francés en Annales, E.S.C., vol 44, núm. 3, 1989), págs. 252-310. 
tantes, otro sector socio-económico compuesto principalmente por rancheros y pequeños y medianos campesinos, artesanos urbanos, traficantes y arrieros ${ }^{68}$ disputándose entre ambos sectores el propio control del mercado.

Garavaglia realiza un análisis del mercado interno de México y Perú igualmente a través de las alcabalas, tratando de medir cuantitativamente el peso que pudieron tener las importaciones europeas en dicho mercado y el lugar que ocupa en este sentido la producción interna, ya sea local, regional o intercolonial. El trabajo destaca el valor de la producción interna, como el segmento más importante en los intercambios producidos al interior del espacio colonial, frente "a la participación relativa de las mercancías europeas en el conjunto de los intercambios del mercado interno colonial". ${ }^{9}$

Otros autores que desde fechas muy tempranas trataron el tema de la alcabala para su estudio o que la utilizaron como fuente son: Smith, Moreno Toscano, Pastor e Izard. ${ }^{70}$ A raíz de estos trabajos y, sobre todo, de los de Assadourian primero y los de Grosso y Garavaglia después, se sucedieron otros donde la alcabala hacía su aparición de forma sistemática al ser empleada o consultada para el estudio de los mercados regionales, en los que la producción, el intercambio y el consumo iban a mantener una complejísima relación.

Del estudio de los mercados coloniales para el Alto Perú por Enrique Tandeter, destacamos sus trabajos junto a Wilma Milletich, Ma. Matilde Ollier y Beatriz Ruibal sobre el mercado de Potosí en el siglo XVIII, ${ }^{71}$ en los cuales se utilizó la serie completa de libros de alcabalas en la Aduana de Potosí, desde 1779 hasta 1810 — en el Archivo General del la Nación de Buenos Aires-. Sobre las posibilidades que ofrece la fuente señalan que

68 Grosso y Silva Riquer, Mercados..., pág. 303.

69 Garavaglia, Juan Carlos: "El mercado interno colonial a fines del siglo XVIII: México y el Perú”, en Heraclio Bonilla, ed.: El sistema colonial en la América española, Barcelona, Crítica, 1991, pág. 232.

70 Smith, R. S.: "Sales Taxes in New Spain, 1575-1770" en Hispanic American Historical Review, XXVIII: 1, 1948; Moreno Toscano, A.: "Economía regional y urbanización: tres ejemplos de relación entre ciudades y regiones en Nueva España a finales del siglo XVIII" en Calnek, Edward E., Borah, Woodrow y otros: Ensayos sobre el desarrollo urbano de México, México, 1974; Pastor, R.: "La alcabala como fuente para la historia económica y social de la Nueva España" en Historia Mexicana, XXVII, n. ' 1, 1977; Izard, M.: "Metropolitanos, criollos y reformistas. La Nueva España de Revillagigedo (1789-1794)" en Boletín Americanista , XXII, n. o 30, Barcelona, 1980.

71 Tandeter, Enrique, y otros: "El mercado de Potosí a fines del siglo XVIII", en Olivia Harris, Brooke Larsen, Enrique Tandeter (comps.): La participación indígena en los mercados surandinos. Estrategias y reproducción social, siglos XV) I-XX, La Paz, Bolivia, 1987. Publicado después en Mercados e Historia, págs. 165-206. 
"permite analizar en detalle el tráfico de importación al centro minero, los valores y los volúmenes totales, así como las proveniencias regionales servirán para evaluar los efectos de la economía minera sobre el conjunto de la formación social colonial, mientras que las frecuencias de las operaciones y sus valores promedio serán indicadores de las posibilidades de acceso al mercado para productos y traficantes individuales". ${ }^{72}$ La relación entre el giro comercial y el monto total de la producción minera que se da en Potosí, confirman la teoría de un gran centro minero, foco de atracción principal de los comerciantes para trocar sus mercancías en dinero.

Esta relación existente entre minería y comercio ya fue puesta de manifiesto por Assadourian, para quien el auge minero potosino a fines del siglo XVI y los tráficos mercantiles que se daban en torno a él, contribuyeron a una especialización regional y a la mercantilización de ese espacio que él llamó "espacio peruano".

Uno de los trabajos más recientes de E. Tandeter fue presentado junto con W. Milletich y R. Schmit al coloquio internacional de "Circuitos mercantiles, mercados y región en Latinoamérica, Siglos XVIII-XIX", celebrado en México en el año $1993 .{ }^{73}$ En dicho artículo se refuerza la idea de la "cadena de efectos", generados a partir de la minería, pero a la par también plantea nuevas hipótesis: la creciente autonomización de las regiones productoras y circuitos mercantiles respecto de los mercados mineros. Una tesis apoyada fundamentalmente en la idea de que si bien se detecta desde principios del siglo XVII una tendencia descendente en la producción minera potosina, y de la población urbana, ello no tuvo repercusiones uniformes para la comercialización del espacio peruano. ${ }^{74}$ Igualmente esta investigación rechaza la teoría sobre que la producción de la plata determine los precios del sector exportador de cada economía regional, pues para los años de 1780 a 1810 niega que exista una correlación significativa entre dicha producción de la plata, que se recupera en las primeras décadas del siglo XVIII y se incrementa hasta 1800 para después volver a caer, y los precios de los principales productos regionales, "con tendencias generales a la baja" en esos mismos años.

72 Ibídem, págs. 165-166.

73 Tandeter, Enrique; Milletich, Wilma, y Roberto Schmit: "Flujos mercantiles en el Potosí colonial tardío", en Jorge Silva Riquer, Juan Carlos Grosso y Carmen Yuste: Circuitos mercantiles y mercados en Latinoamérica. Siglos XVIII-XIX, México, 1995, págs. 13-55.

74 "Sin embargo, la mercantilización de diversas regiones, empresas y comunidades indígenas del espacio peruano no se retrajo uniformemente debido a la declinación de Potosî”. Ibídem, pág. 15. 
Sobre la participación indígena en los mercados, existen pocos trabajos y se trata, en tal caso, de estudios parciales ceñidos a determinadas regiones. Las investigaciones llevadas a cabo por Tandeter y su equipo, han detectado, pese a la legislación que determinaba la exención del pago de alcabala a los indígenas, la inclusión de éstos en los registros de los libros de alcabalas de Potosí durante el último cuarto del siglo XVIII, lo que nos indica, en primer lugar, que no se beneficiaban de dicha exención. Segundo, y como consecuencia de lo anterior, podemos medir su participación en el mercado potosino para este período. Los autores mantienen la hipótesis de un levantamiento de la exención, a raíz del decreto del visitador José Antonio de Areche en el año 1779, y de su vigencia posterior en Potosí, apoyándose en la abundancia de patronímicos indígenas reflejados en las fuentes de alcabalas y, sobre todo, en los indicios claros de un comercio para satisfacer su propio consumo, como por ejemplo, la comercialización de la coca. ${ }^{75}$

Margarita Menegus ha fijado su atención en fuentes tales como los libros del viento o los libros de tianguis, e incluso en los de alcabalas, para el estudio de la participación indígena en el mercado interno colonial. Dado que con frecuencia eran transgredidas las normas que declaraban exentos del pago de la renta a los naturales, es posible encontrar documentos que corroboran este hecho en los cuadernos de alcabalas, lo cual sirve como indicador para medir la participación indígena en los mercados. La autora señala que no se ha prestado una suficiente atención a las relaciones mercantiles que tuvieron lugar en el mundo indígena, ya que en estudios de este tipo secularmente se ha relegado dicha actividad exclusivamente al repartimiento coactivo de mercancías, y que por tanto el excedente de producción indígena sólo tuvo una salida: el tributo encomendero, transferido directamente a los españoles. ${ }^{76}$ Sin embargo, los estudios de Menegus para el valle de Toluca revelan una importante producción indígena que se comercializaba, y la presencia de los indígenas en los mercados regionales, realizando por lo general operaciones mercantiles al menudeo sobre la base de una gran variedad de géneros. ${ }^{77}$

75 Tandeter y otros, "El mercado de Potosí...", págs. 194-200.

76 Menegus, Margarita: "Fuentes para el estudio de los mercados regionales y la participación de los indígenas en la colonia", América Latina en la Historia Económica. Boletín de Fuentes, n. ${ }^{\circ}$, México, 1994, págs. 11-17.

77 Menegus, Margarita: "La participación indígena en los mercados del Valle de Toluca a fines del período colonial”, en Circuitos mercantiles y mercados..., págs. 136-157. 
Silvia Palomeque ha querido hacer hincapié de forma particular sobre ciertos aspectos de la circulación interregional, y en la necesidad de estudiar los circuitos mercantiles que operan en regiones determinadas. ${ }^{78}$ Realiza dos críticas a trabajos que se han ceñido al estudio de la región de Loja, que han volcado toda su atención sobre las exportaciones de cascarilla, y de forma casi irremediable han vinculado la economía regional a través de estas exportaciones al mercado externo, descuidando, sin embargo, su conexión e integración con el espacio económico interior. La segunda objeción viene dada a los trabajos que se han centrado en medir la circulación mercantil a través del puerto de Guayaquil, y que en su opinión han llevado a generalizaciones bastante peligrosas. ${ }^{79}$ Para Palomeque no se puede negar la existencia de determinadas regiones con un cierto grado de autonomía, pese a existir una dependencia general fuerte de la economía minera del Alto Perú . En su análisis respecto a la región de Cuenca y de los "circuitos interregionales" que operaron en ella, adquiere gran importancia la función que desarrolla Loja y su región, como centros proveedores de mulas para el transporte y tráfico mercantil entre Cuenca y Piura.

Resta por referir el trabajo de Pedro Pérez Herrero, que presenta un enfoque general sobre la integración de los mercados internos de la América colonial y sus relaciones con el exterior ${ }^{80}$ Frente a las posturas emanadas de las teorías de la dependencia, de las posturas colonialistas o de las nacionalistas, Pérez Herrero trata el tema desde el punto de vista de las complejas relaciones interregionales en el espacio colonial. Una de sus teorías más interesante y también más discutida es la que afirma que a fines del siglo XVIII, en la época del reformismo borbónico, hay un cambio de orientación en dichas relaciones volcadas hacia el exterior, rompiéndose lo que se había logrado alcanzar en épocas anteriores, una cierta interrelación espacial e integración económica. Pese a distinguir en cada capítulo las "realidades regionales", a saber: Mesoamérica, Centroamérica, Antillas y Circumcaribe, mundo andino y Brasil, y establecer un cuadro completo mediante cortes cronológicos, el propio autor advierte que tales divisiones temporales no pueden considerarse como períodos "rígidos,

78 Palomeque, Silvia: "Loja en el mercado interno colonial”, en Grosso y Silva, Mercados e Historia, págs. 207-227.

79 “... por ejemplo, sobre la crisis del siglo XVIII y la identificación de todos los valles interandinos como partes de una misma región, dependiente en extremo de la economía minera altoperuana, sin una autonomía relativa y sin alternativas al autoconsumo". Palomeque, "Loja en el mercado interno...", pág. 210.

80 Pérez Herrero, Pedro: Comercio y Mercados en América Latina Colonial, Madrid, 1992. 
acabados y completos". Interesa de forma particular los dos modelos de interpretación propuestos para el estudio de las relaciones de mercado: el modelo solar o de olla a presión caracterizado "por la constitución de un espacio polarizado, con una relativa complejidad en la jerarquización urbana y en la estructura social y con la presencia de flujos comerciales internos" - estudia fundamentalmente las repercusiones que tuvieron los núcleos urbanos y los reales de minas sobre la organización de los espacios internos coloniales-; y el modelo dendrítico o de embudo, que explica la articulación interna a través de variables exógenas, tratándose por tanto de economías orientadas fundamentalmente hacia fuera —una reducción en la producción interna se transformaba en una disminución de los volúmenes comerciales externos- ${ }^{81}$

\section{A modo de conclusión}

“Son buenas las regiones para pensar?”, esta era la pregunta planteada por el profesor Eric Van Young. ${ }^{82}$ Entre muchas razones sugiere el autor dos en especial: una de carácter empírico-histórico, es decir las regiones como categorías empíricas naturales, y la otra, de orden teórico, que sirve para conciliar los problemas que surgen entre las categorías generales y las particulares. ${ }^{83}$ Para dicho autor la delimitación de la región determina la "espacialización" de las relaciones económicas. Partiendo de la idea de que el emplazamiento central de una región puede estar dentro o fuera de la misma, se pueden usar diferentes sistemas o métodos para definir las regiones. Van Young se centra en la estructura de intercambio o los mercados, y a partir de aquí define la región de Guadalajara según la teoría del modelo solar dentro de dicho sistema del emplazamiento central. Se trata de una región muy particular determinada por el área de mercado de Guadalajara y la influencia ejercida en esa zona ante la creciente demanda urbana de alimentos durante el siglo XVIII. En realidad, es una región económica espacialmente muy restringida, básicamente agrícola, que el autor denomina

81 Pérez Herrero, Pedro: "Los factores de la conformación regional en México (1700-1850): Modelos existentes e hipótesis de investigación”. En Región e Historia en México (1700-1850), México, 1993, págs. 207-236.

82 Véase Eric Van Young: “Are Regions Good to Think?”, en Mexico's Regions. Comparative History and Development, San Diego, 1992, págs. 1-36.

83 Van Young, Eric: "Haciendo historia regional: consideraciones metodológicas y teóricas", en Región e Historia..., págs. 99-122. 
"área de abasto primario" en el perímetro de la ciudad —el hinterland—, ${ }^{84}$ en la cual, la creciente demanda urbana de productos alimenticios básicos, carne y granos principalmente, trajo consigo una expansión de las áreas de abastecimiento y sentó las bases necesarias para la "integración regional".

Siguiendo la categoría de análisis de Van Young, hemos podido observar cómo la región ha estado presente de forma constante en los estudios aquí presentados, y también hemos podido comprobar que la historia regional ha resultado especialmente útil para acercarnos a la problemática del mercado interno colonial. Si consideramos el concepto región en el mismo sentido que lo conoce Van Young, en su forma más útil, como la "espacialización" de una economía, y si tratamos la regionalidad como un concepto dinámico, rechazando la idea de la existencia de regiones estáticas, podemos llegar a análisis de mayor complejidad. Teniendo en cuenta que el estudio regional nos permite hacer hincapié en los elementos económicos, y en las relaciones espaciales que se derivan, la región se constituye en protagonista de los estudios que atienden al mercado interno colonial. La experiencia ha demostrado que los trabajos que se han centrando en la fiscalidad y en los mercados, han logrado excelentes resultados a partir del análisis de tipo cuantitativo y serial centrado en determinadas regiones.

84 Van Young, Eric: La ciudad y el campo..., págs. 26-27. Véase también su capítulo: "Hinterland y mercado urbano: el caso de Guadalajara y su región". En La crisis del orden colonial. Estructura agraria y rebeliones populares de la Nueva España, 1750-1821, México, 1992, págs. 199-245. 